\title{
Evaluation of a Computer Vision- Based System to Analyse Behavioral Changes in High School Classrooms
}

\author{
Hyungsook Kim, Department of Cognitive Sciences, School of Intelligence, Graduate School of Public Policy, HY Digital \\ Healthcare Center, Seoul, South Korea \\ David O’Sullivan, Pusan National University, Busan, South Korea \\ Ksenia Kolykhalova, University of Genoa, Genoa, Italy \\ Antonio Camurri, University of Genoa, Genoa, Italy \\ Yonghyun Park, HY Digital Healthcare Center,, Seoul, South Korea
}

\begin{abstract}
The objectives of this study were to investigate the feasibility of applying computer vision techniques and to analyse changes in behaviour and movement of high school students during class. The study was performed over two phases. Phase 1 focused on developing a feasible method to use computer vision-based techniques in high school classes, and Phase 2 focused on the testing of aromatherapy to affect student movement. All camera data was processed and analysed by OpenPose, Matlab, and EyesWeb. Movement features such as velocity, acceleration, and kinetic energy and postural variables, spinal extension, and neck flexion were calculated. Results of Phase 1 showed significant differences in the overall segment velocity, acceleration, energy, and neck flexion. Similarly, the second phase showed significant differences in velocity, acceleration, and jerk for the left shoulder and elbow joints of the group exposed to aroma. In conclusion, the results show the feasibility of using computer vision techniques in a classroom setting.
\end{abstract}

\section{KEYWORDS}

Behaviour, Education, Movement Characteristics, Stress

\section{INTRODUCTION}

This study is a series of experiments, which is part of the project funded by Ministry of Education of the Republic of Korea and the National Research Foundation of Korea (NRF-2016S1A2A2912583). The project "Effect of olfactory stimulation on extending concentration behaviour patterns in high school students" aimed to 1) investigate the effect of aromatherapy with essentials oils on students during the lessons at school 2) examine how presence of aromatherapy affects the quality of movement of the students and 3) application of computer vision techniques for data processing and analysis for comparison of movement behaviour with and without aromatherapy.

The project is based on a tightly coupled interaction between technical and pedagogical partners, to implement software modules that will be useful in detecting the difference in movement behaviour affected by aromatherapy. This paper summarizes two steps to test the feasibility of using computer 
vision techniques in a high school classroom. The first step was a pilot program focused on testing only 4 participants during class (on 2 days) followed by the second step which focused on the application of using these techniques for video data from 2 different classes. There were a total of 12 fifty-minute class periods for 3 high school subjects (social science, mathematics, and geography), spread out over 4 days (Class A without aroma during both days (control group) and the Class B without aroma on the first day and with aroma on the second day (experimental group). These preliminary studies allowed us to progress to a series of pilot tests using computer vision techniques applied to subjects during actual high school classes. A further aim is to expand the investigation to different approaches, which will be implemented in the framework of the Project "Effect of olfactory stimulation on extending concentration behaviour patterns in high school students".

Education in Korea is very highly ranked among the OECD countries (Fair Reporters 2015), however it is also well known that the educational environment creates high levels of stress for the students, which can lead to various mental issues (Lee, Puig, et al., 2010; Lee, Puig, et al., 2013). In addition to educating, teachers at schools are expected to alert parents/guardians if any student has any emerging mental issues, shown by adverse classroom behaviour, that affects their learning (Lee, Hong, Espelage, 2010; Park, Schepp, et al., 2006). As computer vision techniques can detect differences in emotions and behaviours (Camurri, Canepa et al., 2016), we aimed to investigate if similar computer vision techniques, applied to video recordings of an actual classroom in high school, can detect differences in behaviour and movement characteristics of the students.

It is reported that understanding and quantifying human behaviour and movements are key in the early diagnosis of both mental and physical health problems (Beniczky, Polster et al., 2013; Bustamante-Bello, Ruiz-Soto, Ramírez-Mendoza, 2016; Kim, 2017). However, even though some wearable devices have been developed for early detection of diabetes, Parkinson, breast cancer (Cyrcadia Health ltd., USA), hypoglycemia (HealthPatch from VitalConnect, USA), heart disease (Polar, USA) many of these devices are invasive and relatively expensive. In this study, the experimental settings were based on non-intrusive data collection, i.e. through HD video camera recordings. For post processing of the recordings, we used OpenPose, a computer vision technique developed in Carnegie-Mellon University (Zha, Taniguchi et al., 2009; Ramakrishna, Munoz et al., 2014) for estimation of position of joints from $2 D$ video data. Matlab was then used for processing the positional data and tracking of the subjects, and EyesWeb was used to extract certain movement features. Finally, we performed a statistical analysis on the extracted movement features in order to determine the difference between conditions with and without aromatherapy. This article describes the methods, results and discusses the limitations of using computer vision techniques for an automated student's behaviour analysis.

\section{METHODS}

\section{Participants}

The initial experimental procedure and settings were approved by University's Institutional Review Board (IRB) for project at a local high school. Through numerous discussions and meetings between the researchers, high school principle, vice principle and teachers, we refined the experimental procedure according to the setting. The newly agreed upon experimental procedures, were then resubmitted and approved by University's IRB.

For the first data collection session, one high school class with a total number of 15 students (with an age group between 15-16) participated in experimental recordings, during the extra-curricular class (subject: Social Studies). Even though all 15 students and their parents/guardians give their permission to be recorded, only a group of 4 students sitting in the front row were selected because of their proximity to the cameras, i.e. their upper body could be clearly seen in the recording. Some of the students in the second row were more difficult to see as the person in front obscured them from 
the cameras full view. Likewise, for the second data collection session, two full classes of 26 and 27 students (high school students grade 1) participated after full written consent and understanding by both the students and their parents/guardians. In the second phase, due to better camera placement, more students could be clearly viewed (up to $7 / 8$ students each recording). As the settings of the experimental recordings were held during usual high school lessons, we were could not interfere with any aspect of the classroom behaviour and or the teaching methods employed by the teachers.

\section{Procedure and Equipment}

Four high definition cameras were installed on four different sides of the classroom, adequately covering the required space. Video was recorded at full HD (1920x1080) at $100 \mathrm{~Hz}$ specifications, and the 4 cameras were synchronized using a Wi-Fi enabled remote control (RM-LVR1 Sony, Japan). To ensure the cameras were not visible, they were mounted just below the ceiling on the wall.

In the first part of the study, the subjects were studied on two separate days: one day without aromatherapy, and another day with lavender essential oil aromatherapy. The video recordings were executed over two days with one-week between them. Recorded subjects, teacher and room settings were the same for both days. On the first day of recordings subjects were instructed on how to use the blood pressure monitor (HuBDIC HBP-700, Rep. of Korea). For the 2 days, they measured their blood pressure prior and post lesson. The duration of the lesson was 90 minutes. On a second day of recordings, subjects were instructed to wear a lavender essential oil filled necklace during the lesson. The lavender essential oil is $100 \%$ pure natural, undiluted and organically produced (Absolute Aromas Organic Lavender Maillette; Botanical species: Lavendula Angustifolia; originated from France). To ensure the comfort and safety, participants were reminded that they could terminate the use of the necklace at any time if they felt uncomfortable.

For the second data collection, two full classes (High school grade 1; aged 15-16 years old) of 26 and 27 students participated in the experimental recordings, during a total of 12 fifty-minute periods. Recording took place during 3 subjects (social studies, mathematics, and geography), over 4 separate data collections days. Class A was the control group and so they were not given any treatment (no aroma) during the two days of data collection for the 3 above mentioned classes. Class B was the experimental group on their first day they were not exposed to aroma but on the second day (one week later) they were exposed to lavender essential oil by using a lavender essential oil filled necklace.

\section{Data Processing}

This subsection provides a description of data processing steps applied to the video data collected during the lessons at school. We present the methods used to manipulate the raw video data in order to extract the position ( $\mathrm{x}, \mathrm{y}$ coordinates) of the main body joints frame by frame of the video and perform tracking of the subjects who participated in the experiment. The extracted skeletal data was then used for calculation of the movement features, from low-level to higher level. These movement features were used to investigate and analyse the effect of introducing the aroma-therapy complex during the lesson on the behaviour of the student. In other words, we were trying to apply non-intrusive visual observation and the estimation of an affective parameter using a recorded video (RGB) signal, to determine student engagement from upper-body movement and then compare the difference between the classrooms setting, with introduction of aromatherapy complex during the lesson and without. The framework for data processing had the following workflow, data segmentation, articulated human pose estimation, tracking and matching of subjects, then low- and high-level feature extraction.

\section{Initial Video Data and Data Segmentation}

For phase one and two, the recorded data set consisted of the video recordings done by four cameras to capture the movement as accurately as possible. The phase one recordings were separated according to classroom settings: 1) "Day 1" - No Aromatherapy Setting, 2 video recordings for each camera; 
Table 1. Design of the second test showing the testing schedule and the corresponding classroom group

\begin{tabular}{|l|l|l|}
\hline Days & Class Room A (Control) & Class Room B (Experimental) \\
\hline 1 & No Aromatherapy & \\
\hline 2 & No Aromatherapy & \\
\hline 3 & & No Aromatherapy \\
\hline 4 & & Aromatherapy \\
\hline
\end{tabular}

2) "Day 2" - Aromatherapy Setting, 2 video recordings for each camera. To ensure high quality the cameras were set to record at a resolution of 1920x1080 with a sampling rate of 100 frames per second.

For the phase two recordings, the initial recordings were separated according to the classroom settings (Table 1). For consistency of class subjects to be at the same time of day, a 1-week period between each data collection was given between the first and second testing for classroom A and B. One major difficulty while designing and performing the data collection was that as we were testing during high school class, we could not control the class content, and how the teacher taught the class. However, we tried to maintain as much consistency by having the same teachers teach at the same class times for both of the class A and B.

In order to increase the reliability and consistency of the data, upon the recommendations of the local pedagogy experts (a group of both university professors and the high school teachers) the initial and last 10 minutes of the recordings removed (30 minutes remaining to analyse). After checking the accuracy of the data, the video recordings were reduced in size to increase processing speed, the recordings were segmented and converted: the audio channel deleted; video recordings segmented into smaller parts of $10 \mathrm{~min}$ each: format converted from $\mathrm{mp} 4$ to avi; and the properties downscaled to $1280 \times 720$ with a $30 \mathrm{fps}$ frequency.

\section{Human Pose Estimation}

In order to estimate the positions of each subject we used a Convolutional Pose Machine developed by Shih-En Wei, Varun Ramakrishna, Takeo Kanade - The Robotics Institute Carnegie Mellon University (Ramakrishna, Munoz et al., 2014). Carnegie Mellon University Convolutional Pose Machine is a novel technique, that consists of deep architecture for estimating articulated poses (Ramakrishna, Munoz et al., 2014). The software is open source available for research purposes. Convolutional pose machine was recently developed for the task of articulated pose estimation based on the earlier developments by Carnegie Mellon University: pose machine. Pose Machine is a technique that uses the inference machine architecture that allows it to incorporate high-capacity supervised predictors, resulting in good pose estimation performance (Zha, Taniguchi et al., 2009). Convolutional pose machines adopt the benefits of architecture of pose machine such as, the implicit learning of long-range dependencies between image and multi-part cues, tight integration between learning and inference, a modular sequential design - and then combined with the advantages afforded by convolutional architectures: the ability to learn feature representations for both image and spatial context directly from data; a differentiable architecture that allows for globally joint training with backpropagation; and the ability to efficiently handle large training datasets (Figure 1).

The convolutional pose machine allows the estimation of the positions of 18 body joints, if the full body is imaged, these body parts are called pose key points. Based on the specifics of the recordings, we extracted the position of 14 body parts, related to the upper part of the body. The list of pose key points, label correspondence with a body part are nose, neck, right and left shoulder, elbow, writs, hip, and eye, with the position of the key points presented in the Figure 2 (right side). 
Figure 1. Application of Convolutional Pose Machine to the high school class students during extra class

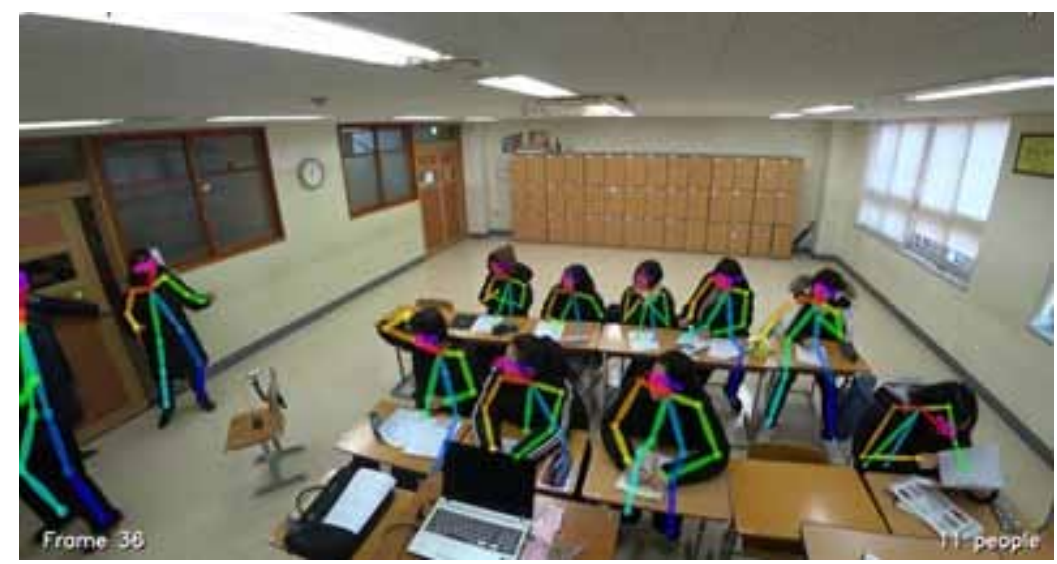

\section{Tracking and Matching of Subjects}

The data output available from OpenPose is JSON files for each frame of the recording separately, that consists of the participant's pose data saved by a custom JSON writer. Each JSON file has an array of objects, where each object has: An array pose_keypoints_2d containing the body part locations and detection confidence formatted as $\mathrm{x} 1, \mathrm{y} 1, \mathrm{c} 1, \mathrm{x} 2, \mathrm{y} 2, \mathrm{c} 2$. In computing, JavaScript Object Notation or JSON is an open-standard file format that uses human-readable text to transmit data objects consisting of attribute-value pairs and array data types (or any other serializable value). In order to work with JSON files and extract meaningful data, we developed software modules separately in MATLAB (Mathworks) to solve the following tasks: Restructure the data from JSON format to a matrix of values, Rewrite the data of each frame from separate JSON file into one matrix. Eliminate the information of pose data that correspond to the people that we don't need for analysis by setting an upper and lower threshold for positional data. Tracking and matching subjects - locating a moving object (or multiple objects) over time. Each frame had a data output as a separated file, it was not

Figure 2. Key points estimated by the Convolution Pose Machine

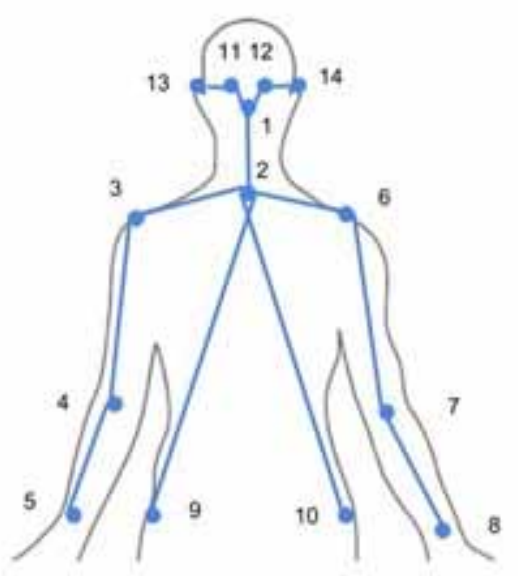


possible to know which person in the video recording corresponded to the positional data of particular frame, i.e. participants could be mixed up. In order to solve this problem, we performed tracking and matching of subjects based on the minimum Euclidean distance of the body centroid, taking in account the assumption that people are sited on chairs and they do not move from their places. In this step we computed pairwise distance with missing elements, since some frames could be missing data, if the joint wasn't tracked.

1) Position Extraction In this step, we computed, filtered and saved the data in text file (.txt) the positional data of $\mathrm{x}, \mathrm{y}$ coordinates of 14 joints named in the section above, for each participant separately, in order to have a complete matrix of position throughout the time frame. The data in .txt format consisted of a matrix of 28 columns by the $\mathrm{N}$-frame numbers for each video segment. 28 columns correspond to $\mathrm{x}$ and $\mathrm{y}$ coordinates of 14 pose key points, separated by tab.

\section{Data Analysis}

\section{Extraction of Low-Level Features}

Considering the limitations of the movements that can be executed during the school lessons, we focused our analysis on upper-body movement features, corresponding to the joints. First, we extracted low-level motion features at a small-time scale (i.e., observable frame-by-frame), such as velocity, acceleration and kinetic energy.

Second, we performed the analysis of the movement features extraction using EyesWeb Platform. The platform is based on EyesWeb XMI, allowing users to perform synchronized recording, playback, and analysis of a multimodal stream of data. EyesWeb XMI is a modular system that allows both expert (e.g., researchers in computer engineering) and non-expert users (e.g., artists) to create multimodal installations in a visual way. EyesWeb provides software modules, called blocks, that can be assembled intuitively (i.e., by operating only with mouse) to create tools and programs, called patches, that exploit system's resources such as multimodal files, webcams, sound cards, multiple displays and so on. In order to extract the low level features out of the pre-processed data files, we developed a module (patch) using EyesWeb. This module consisted of several parts responsible for reading positional data, generation of bi-dimensional point $(\mathrm{x}, \mathrm{y})$ for each of 14 joins, mathematical calculation of the kinematic values and saving the data in a file.

\section{Extraction of Geometrical Features}

We extracted two geometrical features of the upper body, that would potentially capture any behavioural changes which the experiment was monitoring. One variable was on the spinal extension and the other was the neck angle between the head and torso. We calculated spinal extension to estimate the student's level of attention or focus, by measuring how straight the student sat up class. In order to measure the extension of the back, the distance between the position of the neck and the mid-point of hips is computed by considering the matrices of the $\mathrm{x}$ and $\mathrm{y}$ coordinates of the three joints (right and left hip, and Neck) for each frame of a data. The neck angle was used to investigate the change in the movement behaviour during the lesson by analysing the changes of the angle between the head and torso of the student. The movements such as look up to the teacher or look down to the book involve the head moving from up and down, therefore changing the angle between the head and torso. By extracting the positions of markers, we calculated the angle between the two vectors, one vector from point head (Barycentre of the Head) to neck and another vector from point neck to middle of the hip. 
Table 2. Overall velocity, acceleration, and energy for the summation of each joint

\begin{tabular}{|c|c|c|c|}
\hline & $\begin{array}{l}\text { Overall Velocity } \\
\text { (pxllframe) }\end{array}$ & $\begin{array}{l}\text { Overall Acceleration } \\
\left(\text { pxllframe }{ }^{2}\right)\end{array}$ & $\begin{array}{l}\text { Overall Energy } \\
\text { (energy index) }\end{array}$ \\
\hline & Mean \pm Std. Dev & Mean \pm Std. Dev & Mean \pm Std. Dev \\
\hline Control & $0.292 \pm 0.013$ & $0.028 \pm 0.001$ & $0.190 \pm 0.017$ \\
\hline Aroma & $0.366 \pm 0.019 * *$ & $0.038 \pm 0.001 * *$ & $0.230 \pm 0.025$ \\
\hline
\end{tabular}

${ }^{*}$ significant difference $(p<0.05)$

\section{RESULTS}

\section{Phase One}

The low-level features calculated in this study were the overall velocity, acceleration and energy for each of the joints that were active during the lesson. These joints were neck, left and right shoulder, left and right elbow and left and right wrist. Mean and standard deviation values for each of these joints, was calculated separately for each subject. The Table 1 shows the average and standard deviation of the overall velocity, acceleration and energy. There were significant differences in the overall acceleration between the two conditions $[\mathrm{F}(1,54)=4.53, \mathrm{p}=0.037]$. There was also a significant difference in the overall velocity between the two conditions $[\mathrm{F}(1,54)=4.10, \mathrm{p}=0.047]$. However, there was no significant difference $[\mathrm{F}(1,54)=1.10, \mathrm{p}=0.32)$ reported for the energy as there were substantially large standard deviations between each of the participants (Tables 2 and 3).

The results of the one-way ANOVA show that there was no significant difference for spinal extension $[F(1,30)=0.50, p=0.48]$. However, there was a significant difference between the neck flexion angle between the two conditions $[\mathrm{F}(1,30)=3.61, \mathrm{p}=0.045]$.

Table 3. Spinal Extension and Neck Angle

\begin{tabular}{|l|l|l|l|}
\hline & $\begin{array}{l}\text { Spinal Extension } \\
(\mathbf{p x l})\end{array}$ & $\begin{array}{l}\text { Neck Flexion } \\
(\text { radians })\end{array}$ & $\begin{array}{l}\text { Neck Flexion } \\
(\text { degrees })\end{array}$ \\
\hline & Mean \pm Std. Dev & Mean \pm Std. Dev & Mean \pm Std. Dev \\
\hline Control & $29.29 \pm 7.8$ & $1.17 \pm 0.08$ & $67.16 \pm 4.46$ \\
\hline Aroma & $31.57 \pm 9.53$ & $1.01 \pm 0.04 * *$ & $57.90 \pm 2.11^{* *}$ \\
\hline
\end{tabular}

${ }^{* *}$ significant difference $(p<0.05)$

\section{Phase Two}

We examined if the differences could be noticed for each of the joints of the body separately as a result of the aromatherapy or no aromatherapy respectively for velocity, energy, acceleration and jerkiness. The Mann-Whitney U test was chosen due to possibility of an unbalanced dataset. Data showed significant differences for left shoulder and elbow joints of experimental group in comparison between control and the aromatherapy setting with Mann-Whitney U test with a significance level of $\mathrm{p}<.05$ in velocity $(\mathrm{p}=.026, \mathrm{p}=.037)$, acceleration $(\mathrm{p}=.018, \mathrm{p}=.037)$ and jerk $(\mathrm{p}=.020, \mathrm{p}=.036)$ respectively. There were no significant differences between the control and experimental groups for the energy (Tables 4-7). 
Table 4. Average and standard velocity of the upper joints between the control and aroma groups on the different testing days

\begin{tabular}{|c|c|c|c|c|c|c|c|}
\hline Control Group & NECK & $\begin{array}{l}R_{-} \\
\text {SHOULDER }\end{array}$ & R_ELBOW & $\begin{array}{l}\mathrm{R}_{-} \\
\text {WRIST }\end{array}$ & $\begin{array}{l}\mathbf{L}_{-} \\
\text {SHOULDER** }\end{array}$ & $\begin{array}{l}\mathbf{L}_{-} \\
\text {ELBOW** }\end{array}$ & $\begin{array}{l}\mathbf{L}_{-} \\
\text {WRIST }\end{array}$ \\
\hline Day 1 & $\begin{array}{l}2.21 \pm \\
0.35\end{array}$ & $2.20 \pm 0.4$ & $\begin{array}{l}2.34 \pm \\
0.59\end{array}$ & $\begin{array}{l}2.67 \pm \\
0.79\end{array}$ & $2.27 \pm 0.43$ & $\begin{array}{l}2.36 \pm \\
.057\end{array}$ & $\begin{array}{l}2.66 \pm \\
0.82\end{array}$ \\
\hline Day 2 & $\begin{array}{l}2.16 \pm \\
0.57\end{array}$ & $2.16 \pm 0.57$ & $\begin{array}{l}2.31 \pm \\
0.71\end{array}$ & $\begin{array}{l}2.64 \pm \\
0.85\end{array}$ & $2.19 \pm 0.69$ & $\begin{array}{l}2.55 \pm \\
0.97\end{array}$ & $\begin{array}{l}2.76 \pm \\
1.00\end{array}$ \\
\hline \multicolumn{8}{|c|}{ Experimental Group } \\
\hline Day 1 & $\begin{array}{l}1.6 \pm \\
0.24\end{array}$ & $1.62 \pm 0.25$ & $\begin{array}{l}1.68 \pm \\
0.32\end{array}$ & $\begin{array}{l}1.86 \pm \\
0.46\end{array}$ & $1.60 \pm 0.27$ & $\begin{array}{l}1.67 \pm \\
0.31\end{array}$ & $\begin{array}{l}1.92 \pm \\
0.46\end{array}$ \\
\hline Day 2 & $\begin{array}{l}2.21 \pm \\
0.36\end{array}$ & $2.20 \pm 0.4$ & $\begin{array}{l}2.34 \pm \\
0.59\end{array}$ & $\begin{array}{l}2.67 \pm \\
0.79\end{array}$ & $2.27 \pm 0.43$ & $\begin{array}{l}2.36 \pm \\
0.57\end{array}$ & $\begin{array}{l}2.66 \pm \\
0.82\end{array}$ \\
\hline
\end{tabular}

${ }^{* *}$ significant difference $(p<0.05)$ between control and experimental group

\section{DISCUSSION}

In this study, we showed the feasibility of a computer vision-based system to detect differences in behaviour and movement characteristics of high school students during class. The data successfully showed that when the participants were exposed to lavender essential oil, the aroma condition, there were significant increases in overall velocity and acceleration. Based on detailed observation of the recordings the student's sudden moves tended to be from them re-engaging their attention to the teacher. There were also significant decreases in neck flexion angle which shows the students had a straighter head posture (i.e. sitting up straighter), indicating that they were paying attention to the teacher who was explaining. There were no significant differences in the overall kinetic energy of the joint and spinal extension. After observation of the videos, we hypothesized that the students tended to support their upper body (i.e. trunk) by resting their elbows and forearms on the desk, which fixated their shoulders and extended their spine.

Other research focusing on using computer vision techniques for measuring human stress levels tends to focus on the facial expression, eye movements, head movements (Bakker, Pechenizkiy, Sidorova et al., 2011; Volkmann \& Weekes, 2006; Saneiro, Santos, Salmeron-Majadas, et al. 2014). One of the major drawbacks of using facial expression and eye movements to measure stress levels is that the camera must record at a high resolution (Medioni, Choi, Labeau et al., 2013) to record

Table 5. Average and standard deviation of the acceleration of the upper joints between the control and aroma groups on the different testing days

\begin{tabular}{|c|c|c|c|c|c|c|c|}
\hline Control Group & NECK & $\begin{array}{l}\mathrm{R}_{-} \\
\text {SHOULDER }\end{array}$ & R_ELBOW & $\begin{array}{l}\mathbf{R}_{-} \\
\text {WRIST }\end{array}$ & $\begin{array}{l}\mathbf{L}_{-} \\
\text {SHOULDER** }\end{array}$ & $\begin{array}{l}\mathbf{L}_{-} \\
\text {ELBOW** }\end{array}$ & $\begin{array}{l}\mathbf{L}_{-} \\
\text {WRIST }\end{array}$ \\
\hline Day 1 & $\begin{array}{l}0.19 \pm \\
0.03\end{array}$ & $0.21 \pm 0.03$ & $\begin{array}{l}0.21 \pm \\
0.05\end{array}$ & $\begin{array}{l}0.23 \pm \\
0.07\end{array}$ & $0.19 \pm 0.04$ & $\begin{array}{l}0.21 \pm \\
0.05\end{array}$ & $\begin{array}{l}0.23 \pm \\
0.07\end{array}$ \\
\hline Day 2 & $\begin{array}{l}0.19 \pm \\
0.05\end{array}$ & $0.21 \pm 0.05$ & $\begin{array}{l}0.21 \pm \\
0.07\end{array}$ & $\begin{array}{l}0.24 \pm \\
0.08\end{array}$ & $0.19 \pm 0.06$ & $\begin{array}{l}0.22 \pm \\
0.09\end{array}$ & $\begin{array}{l}0.24 \pm \\
0.09\end{array}$ \\
\hline \multicolumn{8}{|c|}{ Experimental Group } \\
\hline Day 1 & $\begin{array}{l}0.14 \pm \\
0.08\end{array}$ & $0.21 \pm 0.11$ & $\begin{array}{l}0.14 \pm \\
0.08\end{array}$ & $\begin{array}{l}0.16 \pm \\
0.10\end{array}$ & $0.14 \pm 0.08$ & $\begin{array}{l}0.14 \pm \\
0.08\end{array}$ & $\begin{array}{l}0.16 \pm \\
0.10\end{array}$ \\
\hline Day 2 & $\begin{array}{l}0.11 \pm \\
0.09\end{array}$ & $0.21 \pm 0.02$ & $\begin{array}{l}0.13 \pm \\
0.03\end{array}$ & $\begin{array}{l}0.16 \pm \\
0.04\end{array}$ & $0.11 \pm 0.02$ & $\begin{array}{l}0.12 \pm \\
0.02\end{array}$ & $\begin{array}{l}0.14 \pm \\
0.04\end{array}$ \\
\hline
\end{tabular}

${ }^{* *}$ significant difference $(p<0.05)$ between control and experimental group 
Table 6. Average and standard deviation of the Jerk of the upper joints between the control and aroma groups on the different testing days

\begin{tabular}{|c|c|c|c|c|c|c|c|}
\hline Control Group & NECK & $\begin{array}{l}\mathrm{R}_{-} \\
\text {SHOULDER }\end{array}$ & R_ELBOW & $\begin{array}{l}R_{-} \\
\text {WRIST }\end{array}$ & $\begin{array}{l}\mathbf{L}_{-} \\
\text {SHOULDER** }\end{array}$ & $\begin{array}{l}\mathbf{L}_{-} \\
\text {ELBOW** }^{*}\end{array}$ & L_WRIST \\
\hline Day 1 & $\begin{array}{l}0.03 \pm \\
0.006\end{array}$ & $\begin{array}{l}0.03 \pm \\
0.007\end{array}$ & $\begin{array}{l}0.03 \pm \\
0.011\end{array}$ & $\begin{array}{l}0.04 \pm \\
0.014\end{array}$ & $0.03 \pm 0.008$ & $\begin{array}{l}0.03 \pm \\
0.010\end{array}$ & $\begin{array}{l}0.04 \pm \\
0.015\end{array}$ \\
\hline Day 2 & $\begin{array}{l}0.03 \pm \\
0.010\end{array}$ & $\begin{array}{l}0.03 \pm \\
0.010\end{array}$ & $\begin{array}{l}0.03 \pm \\
0.013\end{array}$ & $\begin{array}{l}0.04 \pm \\
0.015\end{array}$ & $0.03 \pm 0.012$ & $\begin{array}{l}0.04 \pm \\
0.018\end{array}$ & $\begin{array}{l}0.04 \pm \\
0.018\end{array}$ \\
\hline \multicolumn{8}{|c|}{ Experimental Group } \\
\hline Day 1 & $\begin{array}{l}0.02 \pm \\
0.004\end{array}$ & $\begin{array}{l}0.02 \pm \\
0.004\end{array}$ & $\begin{array}{l}0.02 \pm \\
0.005\end{array}$ & $\begin{array}{l}0.03 \pm \\
0.008\end{array}$ & $0.02 \pm 0.004$ & $\begin{array}{l}0.02 \pm \\
0.005\end{array}$ & $\begin{array}{l}0.03 \pm \\
0.008\end{array}$ \\
\hline Day 2 & $\begin{array}{l}0.02 \pm \\
0.003\end{array}$ & $\begin{array}{l}0.02 \pm \\
0.004\end{array}$ & $\begin{array}{l}0.02 \pm \\
0.007\end{array}$ & $\begin{array}{l}0.03 \pm \\
0.009\end{array}$ & $0.02 \pm 0.004$ & $\begin{array}{l}0.02 \pm \\
0.004\end{array}$ & $\begin{array}{l}0.02 \pm \\
0.008\end{array}$ \\
\hline
\end{tabular}

${ }^{* *}$ significant difference $(p<0.05)$ between control and experimental group

subtle movements, such as eyebrow movements, gaze detection and tracking, and ability to track 27 facial features such as eyes, mouth, and pupil (Shan et al., 2009). In addition, if the participant moves around dynamically, i.e. changing direction in the control volume, many cameras are needed to accurately record the face (Medioni, Choi, Labeau et al., 2013). Using facial expressions and eye movements is excellent for recording stress levels, when someone is using a computer but could be expensive if this system was to be adapted for a classroom, as realistically each student would have to have a camera installed on their desk for constant facial recognition.

This study highlights that relatively low-cost cameras can provide a sufficient level of quality to use this data for estimating the positions of multiple participants in a classroom setting. However, there many limitations; such as the difficulties of installing multiple cameras in the classroom. One major difficulty is getting permission from minors, guardians/parents, and teachers alike. Additionally, teachers and students may walk around the class which may block the camera view making it harder to get to sufficient data. If students move around the class, it is difficult to distinguish between each of the participants while only viewing the data exported as the positional data of their joints.

With the sensitivity of minor's data, it very difficult to get university hospital's institutional review board permission. Furthermore, even with full institutional review board approval getting permission

Table 7. Average and standard deviation of the Kinetic Energy of the upper joints between the control and aroma groups on the different testing days

\begin{tabular}{|c|c|c|c|c|c|c|c|}
\hline $\begin{array}{l}\text { Control } \\
\text { Group }\end{array}$ & NECK & R_SHOULDER & R_ELBOW & R_WRIST & L_SHOULDER & L_ELBOW & L_WRIST \\
\hline Day 1 & $\begin{array}{l}49.4 \pm \\
1.98\end{array}$ & $47.2 \pm 1.95$ & $46.1 \pm 2.19$ & $\begin{array}{l}51.4 \pm \\
2.83\end{array}$ & $51.8 \pm 2.10$ & $51.5 \pm 2.28$ & $\begin{array}{l}52.9 \pm \\
2.82\end{array}$ \\
\hline Day 2 & $\begin{array}{l}27.7 \pm \\
1.96\end{array}$ & $27.8 \pm 1.96$ & $28.1 \pm 2.27$ & $\begin{array}{l}32.5 \pm \\
2.91\end{array}$ & $27.5 \pm 2.06$ & $28.9 \pm 2.83$ & $\begin{array}{l}31.6 \pm \\
3.23\end{array}$ \\
\hline \multicolumn{8}{|c|}{$\begin{array}{l}\text { Experimental } \\
\text { Group }\end{array}$} \\
\hline Day 1 & $\begin{array}{l}27.8 \pm \\
1.01\end{array}$ & $28.4 \pm 1.05$ & $28.4 \pm 1.12$ & $\begin{array}{l}30.5 \pm \\
1.39\end{array}$ & $27.5 \pm 1.02$ & $28.9 \pm 1.12$ & $\begin{array}{l}32.3 \pm \\
1.47\end{array}$ \\
\hline Day 2 & $\begin{array}{l}20.6 \pm \\
0.67\end{array}$ & $20.4 \pm 0.68$ & $20.4 \pm 0.87$ & $\begin{array}{l}23.6 \pm \\
1.35\end{array}$ & $20.7 \pm 0.68$ & $21.6 \pm 0.78$ & $\begin{array}{l}23.8 \pm \\
1.09\end{array}$ \\
\hline
\end{tabular}

${ }^{* *}$ significant difference $(\mathrm{p}<0.05)$ between control and experimental group 
from the school principal, teachers, parents/guardians and students was even more difficult and very time consuming. If possible, future studies should be expanded to include more subjects and students coupled with tracking a student's academic performance. This would enable the level of concentration and participation to be related to their movement characteristics and how they perform. Additionally, a qualitative and quantitative analysis performed by psychologists specialized in education would be beneficial to see if they can notice any behavioural differences. This would help verify if computer vision methods are a reliable method to distinguish between situations of low and high stress.

\section{CONCLUSION}

In conclusion, this study shows the feasibility of using computer vision techniques and developments in the analysis of video recordings of school lessons. The data shows significant differences between movement kinematics with exposure to Lavender essential oil. While using automated processes for analysing human movement is much faster than traditional biomechanical methods that focus on discrete phases, it is critically important for the user to understand the pitfalls that may occur while analysing continuous data.

\section{ACKNOWLEDGMENT}

This work was supported by Global Research Network program through the Ministry of Education of the Republic of Korea and the National Research Foundation of Korea (NRF-2016S1A2A2912583). 


\section{REFERENCES}

Bakker, J., Pechenizkiy, M., \& Sidorova, N. (2011, December). What's your current stress level? Detection of stress patterns from GSR sensor data. In 2011 IEEE 11th international conference on data mining workshops (pp. 573-580). IEEE.

Beniczky, S., Polster, T., Kjaer, T. W., \& Hjalgrim, H. (2013). Detection of generalized tonic-clonic seizures by a wireless wrist accelerometer: A prospective, multicenter study. Epilepsia, 54(4), e58-e61.

Bustamante-Bello, R., Ruiz-Soto, G., Ramírez-Mendoza, R., Avila-Vázquez, R., Montesinos, L., Noguez-Monroy, J., \& Navarro-Tuch, S. (2016). Health wearables for early detection of frailty syndrome in older adults in Mexico: An informed, structured process for the selection of a suitable device. Procedia Computer Science, 98, 374-381.

Camurri, A., Canepa, C., Ferrari, N., Mancini, M., Niewiadomski, R., Piana, S., \& Romero, M. et al. (2016, September). A system to support the learning of movement qualities in dance: a case study on dynamic symmetry. In Proceedings of the 2016 ACM International Joint Conference on Pervasive and Ubiquitous Computing: Adjunct (pp. 973-976). ACM.

Kim, K. B. (2017). Developing an intelligent health pre-diagnosis system for Korean traditional medicine public user. Journal of Information and Communication Convergence Engineering, 15(2), 85-90.

Lee, J., Puig, A., Kim, Y. B., Shin, H., Lee, J. H., \& Lee, S. M. (2010). Academic burnout profiles in Korean adolescents. Stress and Health, 26(5), 404-416.

Lee, J., Puig, A., Lea, E., \& Lee, S. M. (2013). Age-related differences in academic burnout of Korean adolescents. Psychology in the Schools, 50(10), 1015-1031.

Lee, S. Y., Hong, J. S., \& Espelage, D. L. (2010). An ecological understanding of youth suicide in South Korea. School Psychology International, 31(5), 531-546.

Medioni, G., Choi, J., Labeau, M., Leksut, J. T., \& Meng, L. (2013). 3D facial landmark tracking and facial expression recognition. Journal of Information and Communication Convergence Engineering, 11(3), $207-215$.

Park, H. S., Schepp, K. G., Jang, E. H., \& Koo, H. Y. (2006). Predictors of suicidal ideation among high school students by gender in South Korea. The Journal of School Health, 76(5), 181-188.

Ramakrishna, V., Munoz, D., Hebert, M., Bagnell, J. A., \& Sheikh, Y. (2014, September). Pose machines: Articulated pose estimation via inference machines. In European Conference on Computer Vision (pp. 33-47). Springer.

Saneiro, M., Santos, O. C., Salmeron-Majadas, S., \& Boticario, J. G. (2014). Towards emotion detection in educational scenarios from facial expressions and body movements through multimodal approaches. The Scientific World Journal.

Shan, C., Gong, S., \& McOwan, P. W. (2009). Facial expression recognition based on local binary patterns: A comprehensive study. Image and Vision Computing, 27(6), 803-816.

The Best Education System in the world in 2015. (n.d.). Available online: http://fairreporters.net/world/the-besteducationsystems-in-theworld-in-2015/

Volkmann, E. R., \& Weekes, N. Y. (2006). Basal SIgA and cortisol levels predict stress-related health outcomes. Stress and Health, 22(1), 11-23.

Zha, H., Taniguchi, R. I., \& Maybank, S. (Eds.). (2010). Computer Vision-ACCV 2009: 9th Asian Conference on Computer Vision, Xi'an, China, September 23-27, 2009, Revised Selected Papers (Vol. 5995). Springer. 
Hyung Sook Kim is an Associate Professor in the Department of Cognitive Sciences, School of Intelligence and the Director of the Hanyang Digital Healthcare Center at Hanyang University, Republic of Korea. She received her Ph.D. and Master's degree from Seoul National University in sports biomechanics (Ph.D.) and pedagogy (Masters) in Seoul, Republic of Korea. Her interests are affordance design in Human computer interaction, Laban Notional Analysis for recording human movement and the development of visual and audio contents for immersion into a task.

David Michael O'Sullivan is a Professor in Sports Engineering in Pusan National University, in Busan, Republic of Korea. He received his Ph.D. and M.S. in sports biomechanics from Seoul National University, Seoul, Republic of Korea. He read an undergraduate from Trinity College Dublin in Manufacturing and Mechanical Engineering in the Republic of Ireland. His interests are the quantification of human movement, development of devices to measure human movement behavior and the measurement of head impact mechanics.

Ksenia Kolykhalova is reading a Ph.D. from the Universita degli studi di Genova, specializing in Computer Engineering. She graduated from a European Double Master Program in Advanced Robotics (EMARO) Ecole Centrale de Nantes in 2014 and Universita degli studi di Genova, Italy. She read her bachelor's degree in engineering and Technology in the field of Automation and Control from Volgograd State Technical University. Her interests are in gait analysis, motion capture and related technologies, and the detection of emotion from motion analysis.

Antonio Camurri is full professor at DIBRIS-University of Genova (Polytechnic School), where he teaches "Human Computer Interaction" and "Multimodal Systems" (Master Degree on Computer Engineering). His research interests include multimodal interfaces, computational models of non-verbal expressive gesture, emotion and KANSEI information processing, non-verbal social behavior, sound and music computing, multimodal interactive systems for theatre, music, dance, museums, and for therapy and rehabilitation. He is the founder and scientific director of InfoMus Lab and of Casa Paganini - InfoMus Research Centre of University of Genoa.

Yonghyun Park is a postdoctoral researcher at the HY Digital Healthcare Center at Hanyang University, Republic of Korea. He received his Ph.D. and Master's degree in sports biomechanics from Seoul National University, Seoul, Republic of Korea. His interests are biomechanics, human movement analysis, human-computer interaction, and promotion of students' active learning. 